\title{
W.B.Yeats: Poet and Astrologer
}

\section{Elizabeth Heine}

William Butler Yeats appears to have begun his study of astrology even before he joined the Hermetic Society of the Golden Dawn in 1890. His earliest surviving astrological manuscripts date to 1888 or 1889 , when he was in his early twenties; they record planetary elements and symbols in elementary lessons, probably undertaken among Madame Blavatsky's theosophists. ${ }^{1}$ For the 1890 s, his manuscripts show more emphasis on readings of tarot cards than on astrological predictions, although the tarot lay-outs are occasionally accompanied by horary charts drawn up for the moment of the reading. Yeats's use of traditional astrology became much more extensive and precise during the Edwardian years, particularly in 1908, when he was using several different notebooks for astrological calculations. Notebooks survive much better than loose sheets, of course, and another, from 1934, preserves what seem to be the latest surviving horoscopes drawn up by Yeats himself, including his own secondary progressions for the following year; ${ }^{2}$ they appear to have been cast in September or October, about the time Virginia Woolf noted Yeats's conversation about the occult in her diary: 'He believes entirely in horoscopes. Will never do business with anyone without having their horoscopes. ${ }^{3}$

Yeats's knowledge and practice of predictive astrology spanned his adult life - he died at the age of 73 in 1939 - but the remarkable flowering of his non-traditional development of astrological concepts came to him with his marriage to Georgie Hyde-Lees in 1917. Mrs Yeats was also a member of the Stella Matutina, as Yeats's branch of the Golden Dawn had come to be called, and proficient in astrology. Soon after their marriage they discovered that she could respond to her husband's questions mediumistically, through automatic writing. What the spirits brought was a whole new system of astrological interpretation, mooncentered and visionary.

Yeats seems to have had visionary expectations for astrology from the start of his studies, as he had for all his magical experimentation with occult systems of symbolism. Yet, to judge from the later manuscripts, he also became fascinated by astrology's objective basis in astronomical cycles. For him however, the patterns were always astrological, and the

Elizabeth Heine, 'W.B.Yeats: Poet and Astrologer', Culiure and Cosmos, Vol. 2 no 1 , Spring/Summer 1998, pp. 60-75. 
changing states of both the world and the individual inextricably linked to the cycles of the planets.

\section{Astrological Symbolism in Yeats's Poetry}

Yeats's specific studies in precise astrological prediction are focused in the journals of 1908, but I will first indicate a few of the astrological themes in his major late poems, to give some idea of how these poems relate to the philosophical system he developed from his wife's automatic writing. Yeats also published these ideas in his late prose, in the work he titled simply A Vision, first published early in 1926, and then again, much revised, in $1937 .{ }^{4}$ Transcripts of the automatic writing have also been published; they make it clear that Yeats's training in traditional western astrology initially interfered with his understanding of the new system. ${ }^{5}$ Thus I will return to Yeats's earlier practices later in the essay, considering ordinary character analysis and basic prediction in a more strictly biographical fashion. For example, his traditional astrological practices certainly affected his choice of a marriage partner, yet it is impossible to say that anyone could have predicted the automatic writing and its results - although it must be considered that Mr and Mrs Yeats themselves, accustomed to invocations of vision, may have approached marriage as something of a union between Magus and High Priestess; there are marriage poems celebrating Solomon and Sheba, and both 'Solomon to Sheba' and 'Solomon and the Witch' were written in 1918, not long after Yeats's marriage. ${ }^{6}$

Yeats's use of astrology in his poetry is at the same time very well known and utterly unrecognized. 'Things fall apart; the centre cannot hold,' is widely quoted from his poem, 'The Second Coming', first published in 1920. It concludes perhaps even more famously: 'And what rough beast, its hour come round at last, / Slouches towards Bethlehem to be born?' The beast is a millennial vision, dependent in the hour of its 'slouching' on Yeats's idea of the Great Year. Within this 'year', based on the complete zodiacal circuit of the precession of the equinoxes, Yeats chose twelve symbolic two-thousand-year divisions, corresponding to the twelve signs of the zodiac, as a measure of changes in civilisations which succeed each other through opposition. This idea is also apparent in 'The Second Coming' and in its associated poems, like the famous sonnet, 'Leda and the Swan', written in September 1923, and 'Two Songs from a Play', which are the pair that open and close Yeats's Resurrection, first published in 1927 and again, revised, in 1931. In the opening song Yeats 
refers to the ritual death of Dionysus, when 'the Muses sing / Of Magnus Annus at the spring', while in the closing one he evokes the Christian era: 'Odour of blood when Christ was slain / Made all Platonic tolerance vain / And vain all Doric discipline.'

In these poems about the changes of civilisations that divide Yeats's Great Year, he takes the birth of Helen of Troy, daughter of Zeus and Leda, as the symbolic beginning of Greek civilisation, and matches that birth to the birth of Christ, son of the Virgin Mary and God, in the usually dove-like form of the Holy Spirit, as the beginning of our own. 'Dove or Swan' is the title of the chapter in A Vision in which Yeats describes the cyclical oppositions he sees in the changes of past civilisations; the sonnet, there called simply 'Leda', introduces the chapter. In 'The Second Coming', the shift from the classical age of 'tolerance' and 'discipline' to the Christian centuries is not celebrated as a coming of peaceful love: 'twenty centuries of stony sleep / Were vexed to nightmare by a rocking cradle ....' Yet when I suggest to readers that they should consider the possibility that, in opposition, the 'rough beast' might be taken as a precursor of a less violent age to come, they are surprised. But Yeats is explicit about his symbolic oppositions; their astrological elements may be more apparent in his symbolic use of the full and the new moon.

In 'Byzantium', which Yeats wrote in 1930 as a pendant for his 'Sailing to Byzantium' of 1926, new moon and full moon shape the stanza featuring the miraculous bird, which, 'Planted on the star-lit golden bough, / Can like the cocks of Hades crow, / Or, by the moon embittered, scorn aloud / In glory of changeless metal / Common bird or petal ....' The scene is 'star-lit' when the moon is new, conjoined to the sun and invisible in itself, leaving the stars as sole luminaries of the night. As in his circular diagram of the moon's phases in the 'Great Wheel' of $A$ Vision, this is the phase Yeats termed wholly 'objective', ruled by fate and tradition, forces outside the self. By contrast, at the full moon all is wholly 'subjective', full of self, ego in a state of glory or beauty, scorning the common. Both of these phases are ultimate, providing alternate routes to timelessness and eternity, to the midnight flames of Yeats's 'Byzantium', where souls are freed from the complexities of 'That dolphin-torn, that gong-tormented sea' of human life. Yeats's oppositional symbols of course expand; full moon and new moon can become the human self and soul, as in the poem of 1928 called 
'A Dialogue of Self and Soul', which was later gathered in the same late volume as 'Byzantium'.

Students of Yeats's poetry can easily learn the essentials of his lunar system in the poem called 'The Phases of the Moon', first published in 1919; Yeats also provided further brief notes on other ideas related to his developed Vision as he published his later poems and plays. On the whole, the collected poetry and plays are so rich in their development of all the associated symbols, without the further prose of $A$ Vision, that some literary critics do little more than dismiss the book as an aberration. Even Graham Hough, analysing this reaction and defending Yeats's use of the ancient occult traditions, still resists the astrological elements of $A$ Vision: 'But there are no astrological claims that the phases of the moon cause or dictate the development of man's nature; it is an appropriate metaphor, no more. ${ }^{7}$ Hough's conclusion seems to me to beg the question, but probably others' avoidance arises partly because sections of the work do look forbiddingly astrological, diagramming and tabling the qualities of all twenty-eight of Yeats's envisioned phases of the moon. Moreover, the static diagrams of a spinning geometry of spirals, cones, and spheres are unilluminating; by contrast, the wider and wider spirals of the falcon in 'The Second Coming', as the bird and the falconer lose contact, are easily visualised. With or without knowledge of A Vision, readers can immediately question whether the spiraling shadows of the desert birds, reeling around the 'rough beast', are incoming or outgoing, or both, at the moment of the 'hour come round at last'. Similarly, mindboggling tables of four-fold faculties and principles - 'mask' and 'will', 'creative mind' and 'body of fate' - all varying in oppositional symmetry for each of the phases, are eclipsed by the masked figures of Yeats's dance-dramas.

Nor do astrologers read A Vision, for one's lunar phase in Yeats's system turns out not to be determined by anything so simple as one's natal moon (the position of the moon for the time and place of one's birth), as would be the case in standard astrology. For Yeats one's phase is instead an 'embodiment' or 'incarnation' in the soul's progression among the historical cycles and individual phases of a cosmological odyssey, which includes passages from death to reincarnation, ideally at successive phases. The automatic writing indicates that in its early days, in the winter of 1917-18, there was more concentration on traditional astrology, and that the Yeatses did have a way to read individual horoscopes in light of the visionary system, but I'm not sure that enough 
64 W.B.Yeats: Poet and Astrologer

evidence remains to replicate their techniques. However, if anyone should decide to read A Vision, I recommend beginning with the first edition. Mrs Yeats did not at that point want her part in the creation of the system to be known, so Yeats invented a wonderful farrago of found manuscripts and lost Arabian tribes, who danced the spinning and spiraling patterns of his envisioned cosmos in the desert sand. The storytelling helps to make the earlier Vision more sensual and more vividly imaginative, if not easier to follow. There are also daimons, male for women and female for men, and in the section entitled 'Dove or Swan', Yeats was willing to look at least a few years into the future.

Yeats dedicated the first version of $A$ Vision to his most visionary friends from his early days in the Golden Dawn. In the revision, he opens with a section called 'A Packet for Ezra Pound', and then explains the role of his wife and the nature of the automatic writing; perhaps as a result, he writes in a more learned and restrained manner. He spent years reading philosophy, science, and religion after the first Vision was written, and now his emphasis is more philosophical and moral. Reminding us of the basic purposes of most philosophies and religions, he defends what he calls his 'stylistic arrangements of experience' by explaining, 'They have helped me to hold in a single thought reality and justice. ${ }^{8}$ His explanation of the basic geometry is much clearer, and briefer; there is a much more extensive account of the history of the Great Year; 'Dove or Swan' is repeated, but the earlier venture into the future is dropped; the Arabian tribes and the daimons are gone, and the overall effect is much drier.

It is interesting to wonder how Yeats might have adapted the later Vision for an audience of astrologers. 'Seven Propositions', printed below, appears in neither edition of $A$ Vision. It was first published by Virginia Moore in her study of Yeats in 1954, taken from a typescript remembered by Mrs Yeats as being later than the revised Vision, but Yeats in fact wrote and revised the manuscript earlier; entitled 'Astrology and the Nature of Reality', it survives in a notebook among poems written in $1930 .{ }^{9}$ In time of composition it falls between the two Byzantium poems, and probably in the midst of some of the major rewriting of $A$ Vision. It needs an audience that knows what horoscopes are, but it moves far beyond ordinary astrology into the metaphysical realm also reflected in the later Vision. Perhaps the most important element in terms of general discussion is the mention of 'freedom' in the seventh proposition. Yeats's use of astrology is not particularly fatalistic;

Culture and Cosmos 
in 'Solomon and the Witch', one of the earlier marriage poems, he speaks of another implied change in civilisations at a moment when 'Chance' and 'Choice' become one. 'Chance' is fate, but for Yeats 'Choice' makes our destinies. The either/or statement in Proposition Five reflects the difference, which is somewhat similar to that between 'self' and 'soul', the first creating a destiny, the second accepting fate.

\section{Seven Propositions ${ }^{10}$}

\section{I}

Reality is a timeless and spaceless community of Spirits which perceive each other. Each Spirit is determined by and determines those it perceives, and each Spirit is unique.

II

When those Spirits reflect themselves in time and space they still determine each other, and each Spirit sees the other as thoughts, images, objects of sense. Time and space are unreal.

III

This reflection in time and space is complete only at certain moments of birth or passivity, which recur many times in each destiny. At these moments the destiny receives its character until the next such moment from those Spirits who constitute the external universe. The horoscope is a set of geometrical relations between the Spirit's reflection and the principal masses in the universe and defines that character.

\section{IV}

The emotional character of a timeless and spaceless Spirit reflects itself as its position in time, its intellectual character as its position in space. The position of a Spirit in space and time therefore defines character.

\section{$\mathrm{V}$}

Human life is either the struggle of a destiny against all other destinies, or a transformation of the character defined in the horoscope into timeless and spaceless existence. The whole passage from birth to birth should be an epitome of the whole passage of the universe through time and back into its timeless and spaceless condition. 


\section{VI}

The acts and nature of a Spirit during any one life are a section or abstraction of reality and are unhappy because incomplete. They are a gyre or part of a gyre, whereas reality is a sphere.

\section{VII}

Though the Spirits are determined by each other they cannot completely lose their freedom. Every possible statement or perception contains both terms - the self and that which it perceives or states.

'Seven Propositions' was written about the time Virginia Woolf described another evening in Yeats's company, in November 1930, remembering his ideas about the current state of poetry: 'indeed I got a tremendous sense of the intricacy of the art; also of its meanings, its seriousness, its importance, which wholly engrosses this large activeminded immensely vitalised man. ${ }^{11}$

\section{Yeats's Horoscope and Practice of Astrology}

Virginia Woolf describes Yeats in full maturity, seven years after he received the Nobel prize; astrologically, his natal chart seems to have long been understood among his family as supporting such intensity and success. The earliest surviving interpretation of Yeats's horoscope was written by his uncle, George Pollexfen, who was also a member of the Golden Dawn, having joined in December 1893. ${ }^{12}$ Yeats was born on July 13, 1865, in Dublin, at 10:40 p.m., a time he noted on one of his charts as taken from the family Bible. Dublin clock-time was in those days 25 minutes earlier than London time, like its sun-time, so the stated birth time accords very closely with Yeats's preferred ascendant of $0^{0} 41$ ' Aquarius. Pollexfen drew up the horoscope in the winter of 1894-95, when Yeats was staying with him in Sligo, on the west coast of Ireland, and it will take us into more general biographical matters. In fact, Yeats's sister Lily copied the analysis without Pollexfen's astrological notes, and when I first read her version I thought it was some kind of family spoof, too good to be true, especially because the opening physical description was, of course, entirely accurate. Pollexfen's notes are based on the standard astrology of the time, however, and show that he took the Moon in Aquarius, well-aspected (in 'trine') to Saturn in Libra, with both Moon and Saturn completing a 'grand trine' with Yeats's Sun-Uranus conjunction in 
George Pollexfen's Horoscope for W.B.Yeats.

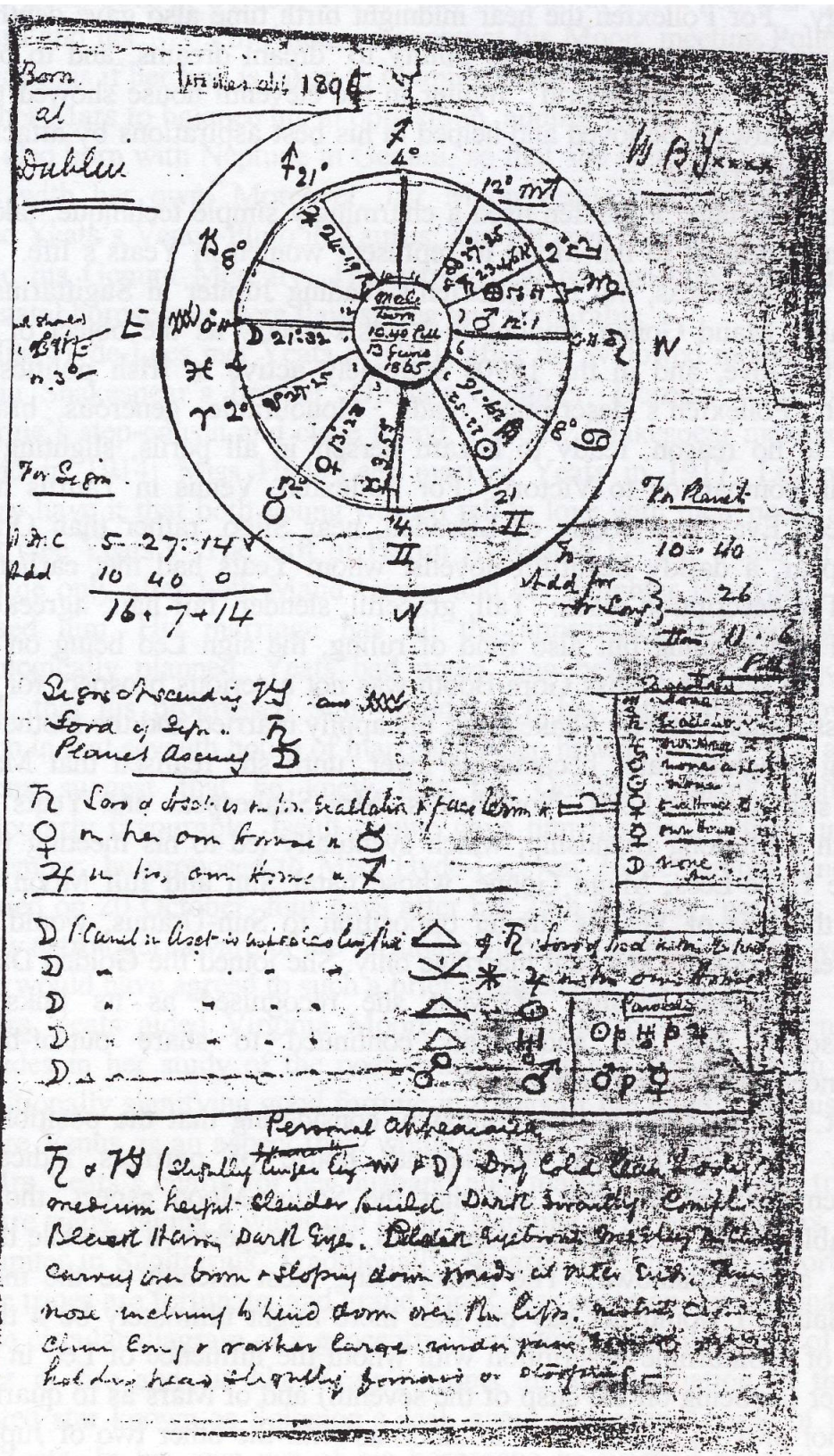

Culture and Cosmos 
68 W.B.Yeats: Poet and Astrologer

Gemini, to account for Yeats's profound imagination and his interest in astrology. ${ }^{13}$ For Pollexfen the near midnight birth time also gave depth to the imagination and the visionary ability to 'dream dreams, and to be a believer in the Unseen World'. Jupiter in the eleventh house showed that Yeats 'will always be loved and helped in his best aspirations by attached and admiring friends'.

As for marriage, Pollexfen used a charmingly simple technique, taking the planets nearest to the Moon to represent women in Yeats's life. The women are nameless, but in Pollexfen's reading Jupiter in Sagittarius is undeniably Maud Gonne, famous in Yeats's poetry as the object of his unrequited love, and in the 1890s extremely active in Irish politics of rebellion. Pollexfen's description reads: 'Honourable, generous, brave, subject to no reason, ready to hazard herself in all perils, slighting all things in comparison to Victory.' For Pollexfen, Venus in Taurus may have been Eva Gore-Booth, of Lissadell, near Sligo, rather than Olivia Shakespear, a darkly beautiful novelist whom Yeats had met earlier in 1894. The description reads: 'Tall, graceful, slender, fair hair, agreeable, musical and winning but also fond of ruling, the sign Leo being on the cusp of the seventh.' Miss Gore-Booth was not a serious prospect for the penniless Yeats, but Mrs Shakespear, unhappily married and the mother of a young daughter, later became his lover, until she realised that Maud Gonne still had his heart. Nonetheless, Mrs Shakespear and Yeats did establish a life-long friendship, which eventually led to his meeting with Georgie Hyde-Lees. Maud Gonne, whose natal Sun and full Moon fell across the axis of Yeats's Jupiter opposition to Sun-Uranus, would for many years consider spiritual marriage only. She joined the Golden Dawn briefly, resigning because of what she recognised as its links to Freemasonry, but she and Yeats continued to share out-of-body experiences and visionary dreams. ${ }^{14}$

What is fascinating is that Pollexfen, considering that the position of Yeats's Mars in Leo in his seventh house of partners indicated disagreements and quarrels, and that the Saturn-Moon aspect, though favourable, might mean no marriage at all, still suggested a possible third woman, as yet unknown: "The planet being most friendly to the moon being Saturn I would not say but that there might ultimately be a third person of a Saturnine description with whom the influence of Leo in her character (as being on the cusp of the seventh) and of Mars as to quarrels might not prove so great a bar to union as with the other two of Jupiter and Venus.' Pollexfen's forecasting seems not altogether wrong. Georgie 
Hyde-Lees, born in October $1892,{ }^{15}$ had her Sun in Libra conjunct Yeats's Saturn and her Mars in Aquarius conjunct his Moon, meeting Pollexfen's suggestions if her Sun is taken to illuminate and strengthen Yeats's Saturn, and her Mars to balance his in opposition, adding vigour to his Moon. She was also born with Neptune in Gemini, so that she matched Yeats's grand trine with her own. Moreover, her Moon-Venus conjunction in Virgo trined Yeats's Venus-Pluto in Taurus, and her own Saturn, early in Libra, trined his Gemini Mercury. The astrological relationships between their two natal horoscopes were thus strong and favourable.

Miss Hyde-Lees met Yeats in 1911, after her widowed mother married Olivia Shakespear's brother. Olivia's daughter, Dorothy, thus became Georgie's step-cousin and close friend. Dorothy Shakespear married Ezra Pound in 1914; Miss Hyde-Lees married Yeats in 1917. Legend and poetry have it that both young women fell in love with their poets at first sight (see Yeats's 'The Gift of Harun Al-Rashid'), ${ }^{16}$ but Yeats turned to Georgie only after both Maud Gonne and her daughter Iseult had finally refused him. His marriage has all the appearances of having been astrologically planned; Yeats had noted long before, in a notebook of 1901, that his progressed Sun would reach his natal Mars, provoking action in that seventh house of marriage, when he was 52, in 1917, and his actions suggest that he knew that the October transits would be particularly favourable. Iseult Gonne gave him her final refusal in midSeptember, he proposed to Miss Hyde-Lees on 26 September, and they married on 20 October, four days after her 25th birthday; perhaps only a fellow astrologer, aware of the fortunate planetary transits for the wedding date, would have agreed to such a brief engagement.

Mrs Yeats aided Virginia Moore with the astrological elements she provides in her study of the poet, which notes his grand trine in air as 'traditionally signifying good fortune in things of the mind', and his Mars square Venus as an aspect that 'would menace his affectional life'. ${ }^{17}$ One of Mrs Yeats's charts for her husband also marks another grand trine, in the fire signs, taking a wider orb to link Neptune in Aries and Mars in Leo to Jupiter in Sagittarius. Traditionally, squares are tense and unfortunate, while trines are fortunate, and grand trines, less common, exceptionally so; in the circular diagram of a geocentric horoscope, a combination of grand trines in fire and air like Yeats's forms an approximation of the six-pointed star known as Solomon's seal, again suggesting a role of Magus for Yeats. In his own use of his 
70 W.B.Yeats: Poet and Astrologer

horoscope he worried most about his quarrelsome Mars, noted by Pollexfen and by Yeats himself among his memoirs, where he considers anger his 'worst fault, rooted in Mars opposite Moon' ${ }^{18}$ There is no evidence that Yeats ever knew that Pluto, discovered in 1930, was exactly conjunct his Venus, and thus in square to both his Moon and Mars; it is a placement that astrologers would now interpret as contributing greatly to his anger and to the entanglements and intensities of his love affairs, but for Yeats it appears that Mars carried the burden.

It is against this background that the grand trine in air signs formed by the transiting planets on the wedding day should be considered. Uranus was in Aquarius, conjunct Yeats's Moon and George's Mars; Jupiter was in Gemini conjunct George's Neptune and just past Yeats's Mercury; the Sun was just past their Sun-Saturn conjunction in Libra. Thus their grand trines were matched by these major transiting planets, a kind of doubling and tripling of fortunate angles. Moreover, transiting Saturn was conjunct Yeats's troublesome Mars in Leo, adding stability to the long awaited conjunction of his progressed Sun and natal Mars. Saturn is often associated with ill fortune, with restriction and hard times and old age, but Yeats's natal Saturn is part of his fortunate grand trine in air, so the transit could be accepted as supportive of his late acceptance of the responsibilities of marriage. If, like Pollexfen, we take the planets as representatives of people, Saturn also suits the age of the groom. Of the two feminine planets, transiting Venus - a loving young woman - was in Sagittarius, trine Yeats's Mars-Saturn-progressed Sun combination in Leo, and the Moon, goddess of marriage and all things female, was also in Sagittarius, approaching Yeats's fortunate Jupiter, itself in trine to George's Jupiter in Aries.

The outer planets change their positions slowly, so it would have been the transiting positions of the Sun and the even swifter Moon that made October 20 a particularly acceptable Saturday for the Yeats wedding. Four days later, when the automatic writing brought the beginnings of $A$ Vision, there was a very precise emphasis on Mercury and Uranus, planets astrologers associate with communication and heightened mental activity; Uranus adds qualities of the unexpected, the unusual, the extraordinary. On October 24, Mercury was transiting their joint SunSaturn conjunction in Libra, and the transiting Sun was conjunct George's own natal Mercury; the Moon had reached Aquarius and was approaching their Moon-Mars conjunction, where transiting Uranus was still stationary, just before its return to forward movement. Considering 
the results of the automatic writing, so important to the power of Yeats's later poetry, the marriage seems to have been something of an astrological gift from the universe to Yeats, or perhaps a gift from the gods of astrology to the gods of poetry. That, at least, could have been Yeats's reasoning.

One last quotation, from Yeats's technical studies of 1908, will help to show that his knowledge and practice of astrology was acute enough to determine his timing for his marriage. It also reminds us that his knowledge of astrology was by no means wholly visionary, that the grand cycles and spirals of his later poetry grew from a more ordinary investigation of planetary correspondences and a belief in the wholeness of nature. In 1907 and 1908, Yeats began to test primary directions, those that depend upon exact rectification of the birth time, so that the mundane turning of the earth and the angles of the ascendant and midheaven can be used for prediction. It is a symbolic degree-for-a-year method that can be calculated from the natal chart alone, while secondary directions use the day-for-a-year method, dependent on an ephemeris to track planetary movements for the days after birth. Primaries were also quite difficult to calculate, especially since proportional semi-arcs were used to take account of planetary declinations, and at this point Yeats turned to the professionals. He ordered a ten-year set of primary directions and secondary progressions from James Wallace, who worked as 'Mercury', ${ }^{19}$ and then had the eleven secondary charts that Wallace sent him, covering the span from January 1907 to June 1917, beautifully bound, with blank pages interspersed for his own use. He listed the primaries, both as calculated by Wallace and by another professional, Claude Dumas, on pages facing the Wallace charts, and added his own calculations and predictions as the years went by.

It seems to have been the Wallace notebook that Yeats was using in 1908, when he mentioned a 'portfolio of calculations' in a little essay he dictated to Lady Gregory, entitled 'The Return of the Stars' ${ }^{20}$ This was not published until the 1960s, long after his death, but it shows his interest in the exact timing of predictions. The primary direction he refers to was a Sun-Mars parallel; 'Mars in his daily motion' was the transiting Mars, conjoining his natal ('radical') Uranus. The essay was dictated on 24 May 1908; the letter Yeats wrote as the transit of Mars became exact was published in The Dublin Evening Mail on 21 May. ${ }^{21}$ As an early expression of Yeats's belief in the effects of the planetary cycles, 'The Return of the Stars' also serves as a fitting conclusion: 
72 W.B.Yeats: Poet and Astrologer

'I find myself watching the stars more and more. I have noticed a primary aspect, Mars to the Sun, for the month of May, and four days ago was sitting with my portfolio of calculations upon my knee, wondering what quarrel it would bring upon me, and at what hour. I noticed that Mars in his daily motion passed over Uranus radical upon the 21st of May. Uranus radical was in my fifth house, the house of adventure, speculation, and in my case of theatres. I had made up my mind that on the 21 st the thundercloud would discharge itself. It was the 20th, and while the book was on my knee, like the fulfilment of the oracle in a Greek play, my landlord brought me a paper with an attack upon our management of the Abbey Theatre, which took up some hours of the next day replying to. An old thought came back to me - we are completing in this age a work begun in the Renaissance. We are re-uniting the mind and soul and body of man to the living world outside us. Christianity revolted against the nature-worship of the heathens, and gradually, as Christianity completed itself, and especially when the Paradise it set in nature's place began to fade, set the mind of man apart like a pebble where nothing is reflected, a hard and abstract thing, with nature for tempter and breaker. Whether you call that abstract thing the reason or the soul matters very little, for to both alike in the long run when their own sweetness is exhausted comes weariness as they look out upon a world which seems no longer a portion of themselves. What the painters and poets who rediscovered landscape, joyous movement, the voluptuous body, began, the astrologer (who arose with the interpretation of Ptolemy by Placidus a Spanish Monk), and the spiritist and the student of Eastern contemplation are carrying into the very depths of the soul, restoring to us the meaning of the night's mystery, bringing into our houses - for the seance room has but to move into the country to discover that old world - the cloven foot of the faun, the dead who inhabit fields and hills, lucky hours that double time's mystery, and hours that measure the tides of being, setting stars to keep the bounds of pleasure and excitement'.

\section{Glossary of Terms}

Ascendant: degree of the ecliptic rising on the eastern horizon.

Grand Trine: three planets or points connected by trines (see below). the four elements are divided among the twelve signs of the zodiac in accord with these equilateral triangles, in order, from Aries on, of fire, earth, air and water. 
Elizabeth Heine 73

Great Year: the complete cycle of equinoctial precession, now calculated to take 25,872 years.

Primary directions: forecasting method based on the transit of one degree of right ascension across the meridian; the transit of one degree generally represents one year of life.

Secondary progressions: see note 2.

Trine: aspect between planets or points separated by $120^{\circ}$ of celestial longitude, measured along the ecliptic.

\section{Acknowledgments}

Most of the known surviving Yeats manuscripts are available for study in photocopy at the William Butler Yeats Microfilmed Manuscript Collection, Special Collections Department, Melville Library, State University of New York at Stony Brook, Long Island. The manuscripts I will be referring to are for the most part unpublished and unstudied, and I am very much indebted to the librarians at Stony Brook, who in their indexing have made it easier to find the bulk of the astrological manuscripts. Originals referred to which are not in the possession of Yeats's family are noted below. I am very grateful to Anne Yeats and Michael Yeats for their permission to study the originals in their libraries, and to refer to them.

The originals of George Pollexfen's horoscopes - usually pencilled drafts - are in Michael Yeats's library, and the illustration here is reproduced with his permission. Pollexfen's notes, 'Written about 1894' and 'W B Yxxxx', may both have been added later; anonymity seems to have been the custom when charts might be used in teaching or learning. 'Personal Appearance', although clearly 'Saturnian', also resembles pictures of the young Yeats. It reads: 'Saturn and Capricorn (slightly tinged by Aquarius and Moon). Dry cold lean body, medium height, slender build. Dark swarthy complexion. Black hair, dark eyes. Black eyebrows meeting in centre, curving over brow and sloping downwards at outer ends. Thin nose inclined to bend down over the lips, nostrils closed, chin long and rather large underjaw somewhat projecting, holding head slightly forward and stooping.' Lily Yeats's transcription of Pollexfen's analysis has been published in The Collected Letters of W.B.Yeats, Volume One, 1865-1895, ed. John Kelly and Eric Domville (Oxford: Clarendon Press, 1986), pp. 422-23. For a copy of Yeats's natal chart 'in his own hand', see my earlier article, "W.B. Yeats' map in his own hand", Biography, 1, No. 3 (1978), 37-50.

\section{References}

1.Yeats's Autobiographies cover his important early relationships with theosophy and the Golden Dawn. His sources of occult knowledge include Madame Blavatsky's Isis Unveiled (New York 1877) and the secret lessons and rituals published in Israel Regardie's The Golden Dawn (1937-40); among the latter are segments duplicated in Yeats's early manuscripts, like that on the Golden Dawn methods of reading tarot cards. One of the first-level requirements for the Golden Dawn was the ability to cast and interpret horary charts, but further study of astrology, although encouraged, was not required. Members who were adept would advise and tutor others who were interested. 
74 W.B.Yeats: Poet and Astrologer

2. Secondary progressions are a forecasting tool in which the planetary positions on each day after birth represent the equivalent year of life. Thus the planets on the tenth day after birth represent the tenth year after birth. See also glossary of terms.

3. The Diary of Virginia Woolf, Volume IV: 1931-35, ed. Anne Olivier Bell, assisted by Andrew McNeillie (London: The Hogarth Press, 1982), p. 257 (26 October 1934). Yeats's 1934 notes are in a manuscript book used primarily for poetry; it shows his addresses as the Savile Club in London and Riverdale in Dublin, and is now in the John J. Burns Library, Boston College, Chestnut Hill, Massachusetts.

4. The first edition of $A$ Vision was published in London by T. Werner Laurie on 15 January 1926, with a publication date of 1925; a reproduction is available in A Critical Edition of Yeats's A Vision (1925), ed. George Mills Harper and Walter Kelly Hood (London: Macmillan 1978).

5.Yeat's Vision Papers, ed. George Mills Harper et al. 3 vols. (London: Macmillan, 1992).

6. Texts and dates of poems used throughout this essay are taken from Yeats's Poems, edited and annotated by A. Norman Jeffares with an appendix by Warwick Gould (Dublin and London: Gill and Macmillan, 1989).

7. Graham Hough, The Mystery Religion of W.B. Yeats (New Jersey: Barnes \& Noble, 1984), pp. 99-100.

8. A Vision, 2nd ed. (London: Macmillan, 1937), p. 25.

9. Yeats's Rapallo Notebook of 1928-30 is now in the National Library of Ireland (NLI 13,581).

10. As published by Virginia Moore, The Unicorn: William Butler Yeats' Search for Reality (New York: Macmillan, 1954), pp. 378-9. See also Richard Ellmann, The Identity of Yeats (Oxford UP, 1970; first published 1954), pp. 236-8.

11 The Diary of Virginia Woolf, Volume III: 1925-1930, ed. Anne Olivier Bell (London: The Hogarth Press, 1980), p. 330 (8 Nov. 1930).

12. Ellic Howe, The Magicians of the Golden Dawn (Wellingborough: Aquarian Press, 1985) p 51. See also Acknowledgments.

13. The type of astrology with which both Pollexfen and Yeats would have been familiar was set out by Yeats's fellow theosophist Alan Leo in his How to Judge a Nativity (London c.1900). For instance, for Sun conjunct Uranus Leo wrote, 'Intuition, independence, originality' (p. 50), and for the Moon in Aquarius: 'This gives some inclination for astrology, fortune telling, dreaming, visions, mediumship, mysticism and the occult generally. Subjects that are unusual, original, eccentric, and novel attract the native. He may become a freemason, or join some secret society, association or brotherhood' (p 85).

Culture and Cosmos 
14. For more detailed accounts of some of these dreams and their astrological correlatives, see Elizabeth Heine, 'Yeats and Maud Gonne: Marriage and the Astrological Record, 1908-09', Yeats Annual 13 (London: Macmillan, 1998), pp. 3-33. Individual biographies of Maud Gonne are usually indexed under her married name, Maud Gonne MacBride. See also The Gonne-Yeats Letters 1893-1938, edited by Anna MacBride White and A. Norman Jeffares (London: Hutchinson, 1992).

15. Georgie Hyde-Lees' birth certificate gives October 17 as the date, but the family always celebrated October 16, and several astrological rectifications exist to support October 16; it was certainly the date Mrs Yeats used in her own calculations, and is used here. After her marriage she was regularly called George, as she preferred.

16. 'The Gift of Harun Al-Rashid' is a narrative poem recounting the arrival of a young bride who brings dreams and visions to an ageing philosopher. It was first published in 1924 and appeared in the first version of $A$ Vision, retitled 'Desert Geometry or The Gift of Harun Al-Rashid', as the introduction to the geometrical section; it was not used in the later Vision. See also Ezra Pound and Dorothy Shakespear: Their Letters, 1909-14, ed. Omar Pound and A. Walter Litz (New York: New Directions, 1984) for the early years of their relationship and the interconnections with Yeats.

17. Moore, The Unicorn, p. 216.

18. W.B. Yeats, Memoirs: Autobiography-First Draft: Journal, transcribed and edited by Denis Donoghue (London: Macmillan, 1972), p. 137.

19. James Richard Wallace, 1852 - 1910?. Wallace's letters to Yeats are extensive. He had fallen on hard times but calculated ephemerides for Raphael and compiled horoscopes on behalf of Alan Leo. Claude Dumas and Hamilton Minchin ('Kymry') also did astrological work for Yeats.

20. In 'Discoveries: Second Series', edited, in slightly different form, by Curtis Bradford, and most easily available in Irish Renaissance: A Gathering of Essays, Memoirs, and Letters from The Massachusetts Review, ed. Robin Skelton and David R. Clark (Dublin: The Dolmen Press, 1965), pp. 82-3. Ellmann (op. cit., p. 296) also quotes the latter portion, from 'An old thought', with some misreadings, like 'Palidus' for Placidus. Bradford and others now identify Placidus de Titus as Italian, but A. J. Pearce in his Textbook of Astrology (1879) terms him Spanish. Yeats's copy of the textbook remains in his library; see Edward O'Shea, A Descriptive Catalog of W.B. Yeats's Library (New York \& London: Garland, 1985).

21. See 'Mr W. Fay and the Abbey Theatre', in Uncollected Prose by W. B. Yeats, Collected and Edited by John P. Frayne and Colton Johnson, vol. 2 (New York: Columbia UP, 1976), pp. 363-4, for Yeats's letter and its circumstances. 